\title{
Atendimento fonoaudiológico intensivo em pacientes operados de fissura labiopalatina: relato de casos
}

\author{
Intensive speech therapy in patients operated for cleft lip and palate: \\ case report
}

\author{
Maria do Rosário Ferreira Lima ${ }^{1}$, Fabiana Borges Leal ${ }^{2}$, Silvana Venâncio da Silva Araújo ${ }^{3}$, Emiliane Ferreira \\ Matos $^{4}$, Camila Queiroz de Moraes Silveira Di Ninno ${ }^{5}$, Ana Teresa Brandão de Oliveira e Britto ${ }^{6}$
}

\begin{abstract}
RESUMO
Devido à carência de fonoaudiólogos para atendimento ao paciente com fissura labiopalatina em várias regiões do Brasil, novos programas de atendimento devem ser desenvolvidos para esses indivíduos. A terapia intensiva de fala tem sido relatada na literatura como uma modalidade alternativa. Este trabalho relata a experiência com alguns casos de atendimento fonoaudiológico intensivo, e compara o desempenho na produção da fala de quatro pacientes operados de fissura palatina, antes e após a terapia fonoaudiológica intensiva. Foram atendidos, no período de férias escolares, três adultos e um adolescente que apresentavam distúrbios articulatórios compensatórios. $\mathrm{O}$ atendimento teve duração de três horas diárias para cada paciente, durante dez dias, divididos em terapia individual e em grupo. No início e fim do período de terapia, os pacientes foram avaliados por uma fonoaudióloga que não participou dos atendimentos. Também foi gravada em vídeo uma amostra de fala espontânea, contagem de 1 a 20 e repetição de uma lista de palavras e frases com fonemas oclusivos orais e fricativos. Todos os pacientes mostraram evolução satisfatória na terapia intensiva, com adequação dos fonemas trabalhados na fala dirigida, necessitando ainda de acompanhamento fonoterápico para sua automatização. A terapia intensiva mostrou ser uma alternativa eficaz e viável nesses casos, podendo também ser uma estratégia durante o início do tratamento fonoaudiológico convencional.
\end{abstract}

Descritores: Fonoterapia; Fissura palatina; Fala/terapia; Insuficiência velofaríngea; Adulto; Adolescente

(1) Fonoaudióloga clínica; Especialista em Motricidade Oral pela Pontifícia Universidade Católica de Minas Gerais - PUC-Minas - Belo Horizonte (MG), Brasil.

(2) Fonoaudióloga da Clínica Terapia do Corpo - Belo Horizonte (MG), Brasil; Especialista em Motricidade Oral pela Pontifícia Universidade Católica de Minas Gerais - PUC-Minas - Belo Horizonte (MG), Brasil.

(3) Docente do Curso de Fonoaudiologia da Universidade Presidente Antônio Carlos - UNIPAC - Barbacena (MG), Brasil; Especialista em Motricidade Oral pela Pontifícia Universidade Católica de Minas Gerais - PUC-Minas Belo Horizonte (MG), Brasil.

(4) Docente do Curso de Fonoaudiologia da Faculdade de Estudos Administrativos de Minas Gerais - FEAD - Belo Horizonte (MG), Brasil; Fonoaudióloga do Centro de Tratamento e Reabilitação de Fissuras Labiopalatais e Deformidades Craniofaciais/Hospital da Baleia - CENTRARE - Belo Horizonte (MG), Brasil.

(5) Docente do Curso de Especialização em Motricidade Oral da Pontifícia Universidade Católica de Minas Gerais - PUC-Minas - Belo Horizonte (MG), Brasil; Fonoaudióloga do Centro de Tratamento e Reabilitação de Fissuras Labiopalatais e Deformidades Craniofaciais/Hospital da Baleia - CENTRARE

- Belo Horizonte (MG), Brasil; Pós-graduanda em Lingüística pela Universidade Federal de Minas Gerais - UFMG - Belo Horizonte (MG), Brasil.

(6) Docente do Curso de Fonoaudiologia e do Curso de Especialização em Motricidade Orofacial da Pontifícia Universidade Católica de Minas Gerais PUC-Minas - Belo Horizonte (MG), Brasil; Pós-graduanda em Lingüística pela Pontifícia Universidade Católica de Minas Gerais - PUC-Minas - Belo Horizonte (MG), Brasil.

Trabalho realizado no Centro de Tratamento e Reabilitação de Fissuras Labiopalatais e Deformidades Craniofaciais/Hospital da Baleia -CENTRARE - Belo Horizonte (MG), Brasil.

Endereço para correspondência: Maria do Rosário Ferreira Lima. R. Dr Romualdo, 520/101, Bairro São Mateus, Juiz de Fora - MG, CEP 36016380. E-mail: rosarioflima@hotmail.com

Recebido em: 31/8/2006; Aceito em: 15/8/2007

\section{INTRODUÇÃO}

As fissuras labiopalatais (FLP) representam a anomalia congênita mais freqüente na face e podem ocorrer como transtornos isolados ou associados a outras anomalias de gravidade variável ${ }^{(1)}$. Estudo realizado em 1968, com população escolar de Bauru, revelou uma prevalência de 1:650 nascidos vivos $^{(2)}$. Outro estudo, com o objetivo de estimar a prevalência de fissuras labiopalatais no Brasil, segundo região geográfica e tipo etiológico, realizou o levantamento dos registros de casos de fissura oral entre recém-nascidos, no período de janeiro de 1975 a dezembro de $1994^{(1)}$. Nesse período, foram registrados no país 16853 casos novos de fissura oral, tendo a região sudeste contribuído com $61 \%$ deles. A prevalência foi estimada em 0,19 por 1000 nascidos vivos ${ }^{(1)}$.

A fissura palatina acarreta uma diversidade de transtornos orgânicos, funcionais e estéticos que interferem intensamente na vida dos indivíduos, principalmente no que se refere ao convívio social ${ }^{(3)}$. No entanto, a correção cirúrgica das estruturas envolvidas (lábio, palato ou ambos) não garante a função articulatória normal da válvula velofaríngica ${ }^{3-}$ 4). Aproximadamente, $30 \%$ dos indivíduos podem continuar com alterações de fala ${ }^{(5)}$, que a tornam prejudicada quanto aos aspectos de articulação e ressonância ${ }^{(3-4,6)}$.

Quanto à articulação, encontramos os distúrbios 
articulatórios compensatórios (DAC), como o golpe de glote e a fricativa faríngea, que são utilizados como estratégias para compensar a falta de pressão intra-oral ${ }^{(7)}$. Eles podem substituir determinados fonemas, oclusivos ou fricativos, ou serem articulados em conjunto com o ponto articulatório correto do fonema, o que se denomina, nesses casos, de coarticulação ${ }^{(8)}$. Observa-se que pacientes que apresentam DAC mostram maior freqüência de distúrbios de linguagem, quando comparados com pacientes que não os apresentam ${ }^{(9)}$.

No que se refere à ressonância, a hipernasalidade associada ao escape de ar nasal e à fraca pressão intra-oral em fonemas oclusivos e fricativos, está presente em todos os indivíduos com disfunção velofaríngea (DVF) ${ }^{(5-6)}$. Por ser decorrente do defeito anatômico, a DVF necessita correção física, cirúrgica ou protética, para a sua eliminação. A fonoterapia, nestes casos, só é indicada na presença de incompetência velofaríngea ou DVF específica para um ou mais fonemas $^{(5)}$. Esses indivíduos podem, por outro lado, apresentar uma hiponasalidade, em decorrência de deformidades nasais, ou ainda, uma ressonância mista ${ }^{(10)}$.

Essas alterações resultam em dificuldades comunicativas porque afetam a inteligibilidade da fala, o que chama a atenção do interlocutor para a sua particularidade e dificulta a aceitação do indivíduo nos ambientes familiar, escolar, profissional e social ${ }^{(3-4)}$. Em função disso, o tratamento fonoaudiológico é de fundamental importância para a evolução da fala, principalmente para a correção dos distúrbios articulatórios compensatórios ${ }^{(4)}$. A reabilitação desses casos requer um tratamento interdisciplinar especializado, envolvendo diversos profissionais ligados à área da saúde ${ }^{(10-11)}$. No Brasil, ainda são poucos os profissionais com experiência nessa área e, em contrapartida, são muitos os pacientes que necessitam da reabilitação ${ }^{(12)}$.

O Conselho Regional de Fonoaudiologia - $6^{\text {a }}$ região fez um levantamento, em 2002, para verificar a localização e o número de fonoaudiólogos inscritos e atuantes na $6^{\mathrm{a}}$ região ${ }^{(13)}$. Constatou que, neste ano, Minas Gerais contava com 1674 profissionais, sendo que a maior parte destes concentrava-se na Região Central ${ }^{(13)}$. Além disso, o Estado conta com apenas dois Centros de Referência para tratamento de pacientes fissurados, um em Alfenas (Centro Pró-Sorriso) e outro no Hospital da Baleia em Belo Horizonte (CENTRARE).

Devido à pouca oferta de serviços especializados na área e à grande demanda de pacientes, faz-se necessário desenvolver novas formas de tratamento. Algumas experiências com terapia intensiva têm sido recentemente relatadas na literatura $^{(14-15)}$. É possível verificar que a evolução terapêutica nos indivíduos portadores de DAC, apesar das particularidades de cada caso, tem relação direta com a freqüência da terapia, sendo os programas de terapia intensiva os que oferecem melhores resultados ${ }^{(7)}$. De acordo com a literatura pesquisada $^{(7)}$, a terapia deve ser inicialmente individual e constante, de três a cinco dias por semana. Uma ou duas vezes por semana pode não ser suficiente, mesmo quando os procedimentos apropriados são utilizados. No caso de adultos, atendimentos mais longos, porém inconstantes, não propiciam a prática necessária para adquirir qualquer habilidade nova, porque a evolução terapêutica tem relação direta com a prática diária e freqüiente dos exercícios de forma correta. É necessário, para isso, que os pacientes e seus familiares sejam bem orientados a este respeito ${ }^{(7)}$.

A terapia intensiva tem se mostrado bastante eficaz na eliminação das articulações compensatórias, além de ser uma alternativa para o caso de pacientes que residem em regiões distantes dos grandes centros e que não contam com fonoaudiólogos para seu atendimento ${ }^{(5,15)}$.

Este trabalho teve por objetivo comparar o desempenho na produção da fala de quatro pacientes (adolescente/adulto) operados de fissura palatina e que apresentavam distúrbio articulatório compensatório, antes e após terapia fonoaudiológica intensiva.

\section{APRESENTAÇÃO DOS CASOS CLÍNICOS}

Para realizar esta pesquisa, aprovada pelo Comitê de Ética em Pesquisa da PUC-Minas com registro CAAE 0049.0.213.000-05, foram atendidos, no período de 16 a 27 de janeiro de 2006, no Centro de Tratamento e Reabilitação das Fissuras Labiopalatais e Deformidades Craniofaciais (CENTRARE - PUC-Minas/Hospital da Baleia), quatro pacientes, sendo três adultos e um adolescente, em fonoterapia intensiva (Quadro 1). O atendimento teve duração de três horas diárias para cada paciente, durante dez dias, distribuídas em dois atendimentos individuais intercalados por um atendimento em grupo.

Quadro 1. Caracterização dos casos atendidos segundo a idade, o gênero, o tipo de fissura e a realização de fonoterapia semanal antes do período de terapia intensiva

\begin{tabular}{|llllc|}
\hline Caso & Idade & Gênero & Tipo de fissura & $\begin{array}{c}\text { Fonoterapia } \\
\text { anterior }\end{array}$ \\
\hline 1 & 30 & Feminino & Transforame bilateral & Sim \\
2 & 40 & Masculino & Pós-forame & Sim \\
3 & 31 & Masculino & Transforame bilateral & Sim \\
4 & 12 & Feminino & Transforame unilateral & Não \\
\hline
\end{tabular}

$\mathrm{O}$ atendimento foi realizado por três fonoaudiólogas, especializandas do Curso de Motricidade Oral da PUC-Minas, que receberam aulas teóricas, treinamento prático e supervisão com os mesmos professores, fonoaudiólogos do CENTRARE, experientes no atendimento a pacientes com fissura labiopalatina. Desta forma, garantiu-se a atuação das três profissionais dentro de uma mesma linha de tratamento.

As três fonoaudiólogas, embora presentes diariamente, se revezaram a cada dia, na condução das terapias individuais e em grupo, de forma que os quatro pacientes foram atendidos, ao longo da semana, por todas as fonoaudiólogas. As terapias foram planejadas a cada dia, em conjunto, pelas três fonoaudiólogas, de forma que os atendimentos, individuais e em grupo, fossem complementares.

No primeiro e no último dia, foram realizadas as avaliações de fala, ressonância e escape de ar nasal, conforme protocolo de avaliação do CENTRARE, e filmagem de uma amostra de fala espontânea, contagem de 1 a 20 e repetição de uma lista de palavras e frases com fonemas oclusivos orais 
e fricativos ${ }^{(10)}$. As avaliações iniciais e finais foram realizadas, por uma das fonoaudiólogas da equipe do CENTRARE.

Na terapia individual, foi estimulada a produção correta dos fonemas por meio da conscientização e instalação do ponto articulatório e direcionamento oral do fluxo aéreo com o uso de pistas táteis, visuais, auditivas e cinestésicas. Usouse, para isto, a produção do som isolado, em sílabas, palavras, frases e textos. As palavras, frases e textos utilizados foram escolhidos e adaptados, quando necessário, para que apresentassem, além do fonema alvo, somente sons produzidos corretamente pelos pacientes. Iniciou-se com a estimulação dos fonemas oclusivos orais, seguidos dos fricativos, de anteriores para posteriores, respeitando a dificuldade e necessidade de cada paciente, como por exemplo, explorando palavras de seu uso diário, o seu nome próprio e de seus familiares. Para cada paciente, quatro fonemas foram selecionados inicialmente e trabalhados simultaneamente, até que estivessem adequados no nível da sílaba e outros fossem introduzidos.

$\mathrm{Na}$ terapia em grupo, foram realizados diferentes trabalhos com a finalidade de reforçar os fonemas recém adquiridos, assim como outras atividades que foram percebidas como necessárias aos pacientes, tais como: leitura de pequenos textos; letras de músicas, nas quais foram exploradas as palavras que apresentavam os fonemas já instalados; gravação de fala em fita cassete para que cada um pudesse se ouvir e perceber suas dificuldades; leitura de textos com diálogo e de provérbios populares, estimulando-se intensidade de fala, melodia e entonação; diálogos, mostrando a necessidade de cada um prestar atenção na própria fala; exercícios articulatórios e de relaxamento cervical e global; além da confecção, pelos próprios pacientes, de material para terapia. Estas atividades apresentavam também o objetivo de trazer um descanso entre as duas sessões diárias de terapia individual. Nesses momentos, os pacientes tinham a oportunidade de observar sua fala, a fala do outro, e perceber que suas dificuldades eram semelhantes às de seus colegas. Em várias situações observou-se que um paciente corrigia e ajudava o outro.

Todos os pacientes foram orientados a treinar em casa, diariamente, os fonemas abordados na terapia.

Dos quatro pacientes, três já haviam feito fonoterapia semanal durante aproximadamente seis meses (pacientes 1, 2 e 3). Foi realizado, com estes, um questionário no início e final da terapia. No início da terapia, foi questionado sobre: a cidade onde moravam e a existência ou não de fonoaudiólogos; o tempo e a periodicidade da fonoterapia; se eram cumpridas as orientações da terapeuta referentes ao treinamento em casa; o que achavam da terapia semanal; o que esperavam da terapia intensiva; como viam a própria fala. Ao final, foi questionado sobre o que acharam da terapia intensiva, se perceberam melhora na própria fala e qual das modalidades de terapia considerava mais eficaz.

A terapia intensiva foi avaliada por todos como uma modalidade muito boa, na qual puderam perceber melhor suas dificuldades, devido à freqüência e duração dos encontros e, assim, conseguir uma melhora na fala em pouco tempo. No entanto, reconheceram a possibilidade das duas mo- dalidades terapêuticas co-existirem de forma complementar. Os pacientes sugeriram que a terapia intensiva poderia ser realizada como um módulo inicial, seguido da terapia semanal, para automatização da produção correta dos fonemas na fala espontânea. Perceberam também que, mesmo em se tratando de adultos, a presença de um membro da família na terapia seria importante para ajudá-los em casa no processo de automatização.

A seguir será apresentado cada caso separadamente, com os dados obtidos nas avaliações iniciais.

\section{Caso 1}

L.F., 30 anos, gênero feminino, operada de fissura transforame bilateral. Reside em uma cidade próxima a Belo Horizonte, onde existe fonoaudiólogo atuando. Tinha realizado fonoterapia em sua cidade, há mais de dez anos atrás, mas durante poucos meses. No segundo semestre de 2005, fez terapia semanal no CENTRARE com sessões individuais de 40 minutos. Relatou que não realizava os exercícios em casa todos os dias, devido ao fato de as tarefas domésticas e o cuidado com os filhos ocuparem boa parte de seu tempo. Julgava sua fala boa, porém relatou que somente as pessoas de maior convivência a entendiam bem. Disse ter perdido seu emprego devido às dificuldades de fala. Sua expectativa em relação à terapia intensiva era de que pudesse melhorar sua fala, assim como aprender a falar o nome de seu marido e suas filhas corretamente. Parecia apresentar uma auto-estima muito baixa.

$\mathrm{Na}$ avaliação inicial foi observada a presença de hipernasalidade leve, plosiva dorso médio palatal (PDMP) nos fonemas /t/, /d/; substituições sistemáticas de /v/ por /g/ e de $/ \mathrm{t} \int /$ por $/ \int /$; substituições assistemáticas de $/ \mathrm{t} /$ por $/ \mathrm{k} /$, de /g/ por /k/, de /z/ por /g/, de /s/ por /k/ e de /dz/ por /g/; fricativa faríngea nos fonemas $/ \mathrm{f} / \mathrm{e} / \mathrm{s} /$; fricativa nasal posterior nos fonemas / $/ \mathrm{e} / 3 /$; ronco nasal nos fonemas $/ \mathrm{z} /, / \mathrm{S} / \mathrm{e}$ $/ \mathrm{d} z /$; plosivização dos fricativos associado ao ronco nasal e escape de ar nasal em palavras com /f, /s/ e frases com /p, /t/, /f/, /s/ e /s/.

Durante a terapia individual foram realizados exercícios buscando o direcionamento do fluxo aéreo para cavidade oral e estimulado a produção correta dos fonemas /t/, /d/, /g/, /f/, /v/, /s/, /z/, /S/ e /3/, por meio da conscientização, instalação e fixação destes, com uso de pistas táteis, visuais e cinestésicas. Foram usados sons isolados, em sílabas, palavras e frases. Associou-se neste caso a abordagem fonológica em função das substituições que a paciente realizava.

\section{Caso 2}

A.A.S., 40 anos, gênero masculino, operado de fissura pós-forame. Reside em uma cidade próxima a Belo Horizonte, na qual não existe fonoaudiólogo atuando. Realizou fonoterapia individual semanal no CENTRARE durante seis meses, com sessões de 40 minutos. Relatou que não realizava os exercícios em casa como orientado pelo terapeuta devido ao "tempo curto". Também o fato de ser bem compreendido pelos familiares deixava-o tranqüilo e displicente em relação ao compromisso com a terapia. Disse que a distância entre uma terapia e outra não o motivava para o tratamento e 
que, às vezes, sem perceber, treinava errado em casa durante toda a semana. Em relação à sua fala, tinha consciência de que apresentava com muitas alterações e que tinha hiponasalidade. Sua expectativa em relação à terapia intensiva era de que pudesse melhorar sua fala em pelo menos $50 \%$.

$\mathrm{Na}$ avaliação inicial foi observada a presença de hiponasalidade moderada, PDMP nos fonemas /t/ e /d/; fricativa faríngea nos fonemas $/ \mathrm{S} / \mathrm{e} / \mathrm{s} /$; fraca pressão intraoral nos fonemas /b/, /f/, /v/, /z/, /3/ e /dz/; escape de ar nasal em palavras e frases com /f/, /s/ e / $/$. Além disso, apresentava a velocidade de fala aumentada.

$\mathrm{Na}$ terapia individual foi estimulada a produção correta dos fonemas /b/, /t/, /d/, /f/, /v/, /z/, /S/, /3/ e /dz/, associada ao direcionamento oral do fluxo aéreo.

\section{Caso 3}

C.V., 31 anos, gênero masculino, operado de fissura transforame bilateral. Reside na cidade de Belo Horizonte e já fez fonoterapia individual semanal, durante seis meses, no CENTRARE, com sessões de 40 minutos. Informou que realizava os exercícios em casa, conforme orientação do terapeuta. Considerava o tempo de terapia semanal muito curto. Em relação à sua fala, tinha consciência de que necessitava melhorar principalmente devido ao fato das pessoas não o entenderem. Sua expectativa em relação à terapia intensiva era de que pudesse melhorar sua fala em pelo menos $80 \%$.

Este paciente, além de alterações próprias relacionadas à fissura palatina, apresentava uma fala pouco articulada, com pouca projeção e modulação, não levantava o rosto ao falar, mostrando-se muito introvertido.

$\mathrm{Na}$ avaliação inicial, foi observada a presença de hipernasalidade leve; fraca pressão intra-oral nos fonemas /p/, /t/, /v/, /z/; substituições sistemáticas de /g/ por /d/ e de /S/ por /s/; substituições assistemáticas de /3/ por /z/; fricativa faríngea no arquifonema $\{\mathrm{s}\}$; omissão dos africados $/ \mathrm{t} \int / \mathrm{e} / \mathrm{d}_{3} /$ e dos grupos consonantais; escape de ar nasal em sílabas, palavras e frases com /p/, /t/, /k/, /f/, /s/ e /S/.

$\mathrm{Na}$ terapia individual, foi estimulado o direcionamento oral do fluxo aéreo na tentativa de melhorar a pressão intraoral na produção dos fonemas /p/, /t/, /v/, /z/ e de adequar à produção do arquifonema $\{\mathrm{s}\}$; também foi estimulada a produção correta dos fonemas /g/, / $/, / \mathrm{t} \int /$ e $/ \mathrm{d}_{3} /$. Associou-se também, neste caso, a abordagem fonológica em função dos desvios fonológicos que o paciente realizava.

\section{Caso 4}

E.D.O., 12 anos, gênero feminino, operada de fissura transforame unilateral esquerda. Residente no norte do estado de Minas Gerais e, na região, não existe fonoaudiólogo atuando. Não havia passado ainda por terapia fonoaudiológica e relatou que os colegas da escola zombavam de sua maneira de falar. Por isso, tinha uma grande vontade de melhorar sua fala. Apresentava auto-estima baixa com reações de choro durante a avaliação.

$\mathrm{Na}$ avaliação inicial foi observada a presença de hipernasalidade moderada; PDMP e projeção de língua nos fonemas /t/, /d/; PDMP nos fonemas /g/ e /s/; golpe de glote nos fonemas $/ \mathrm{k} / \mathrm{e} / \mathrm{g} /$; fricativa faríngea nos fonemas /s/, /z/, $\left./ \int /, / 3 /, / \mathrm{t}\right\} /$ e no arquifonema $\{\mathrm{s}\}$; fraca pressão intra-oral nos fonemas /b/, /d/, /f/, /v/, /z/ e /dz/; escape de ar nasal em sílabas com /k/, palavras com /t/, /k/, /f/, /s/, / / e frases com /p/, /t/, /k/, /f/, /s/ e /S/.

$\mathrm{Na}$ terapia individual foi estimulado o aumento da pressão aérea intra-oral nos fonemas /b/, /d/, /f/, /v/, /z/ e /dz/, adequação do ponto articulatório dos fonemas /g/ e /s/; /k/ e /g/; /s/, /z/, /S/, /3/, /t $\int /$ e do arquifonema $\{\mathrm{s}\}$, associado ao direcionamento do fluxo aéreo para cavidade oral. Com esta paciente foi possível usar jogos infantis como estratégias terapêuticas para a motivação da produção correta dos fonemas que estavam sendo estimulados.

\section{Resultados}

Podem-se observar, após a terapia intensiva, melhoras significativas na fala de todos os pacientes que participaram do programa, principalmente em relação aos DAC (Quadro 2).

Quadro 2. Comparação entre os resultados das avaliações inicial e final, de cada caso, quanto aos fonemas alterados, ressonância oronasal e presença de escape de ar nasal

\begin{tabular}{|c|c|c|c|c|c|c|}
\hline \multirow[t]{2}{*}{ Caso } & \multicolumn{2}{|c|}{ Fonemas alterados } & \multicolumn{2}{|c|}{ Ressonância oronasal } & \multicolumn{2}{|c|}{ Escape de ar nasal } \\
\hline & Antes & Depois & Antes & Depois & Antes & Depois \\
\hline 1 & $\begin{array}{c}/ \mathrm{t} /, / \mathrm{d} /, / \mathrm{g} /, / \mathrm{ff} /, / \mathrm{v} / \\
/ \mathrm{s} /, / \mathrm{z} /, / \mathrm{s} /, / \mathrm{z} /, \\
/ \mathrm{t} /, / \mathrm{d} /,\{\mathrm{s}\}\end{array}$ & $\begin{array}{c}|\mathrm{s} /,| \mathrm{z} /, / \mathrm{t} \mathrm{t} / \\
/ \mathrm{d} z /\end{array}$ & Hipernasalidade leve & Hipernasalidade leve & $\begin{array}{c}/ \mathrm{p} /, / \mathrm{t} /, / \mathrm{f} / \\
/ \mathrm{s} /, / \mathrm{s} /\end{array}$ & $/ \mathrm{f} /, / \mathrm{s} /, / \mathrm{J} /$ \\
\hline 2 & /t/, /d/, /s/, /J/ & $/ \mathrm{s} /{ }^{*}$ & $\begin{array}{l}\text { Hiponasalidade } \\
\text { moderada }\end{array}$ & $\begin{array}{l}\text { Hiponasalidade } \\
\text { moderada }\end{array}$ & $/ \mathrm{f} /, / \mathrm{s} /, / \mathrm{J} /$ & $\begin{array}{c}/ \mathrm{t} /, / \mathrm{k} /, / \mathrm{f} /, \\
/ \mathrm{s} /, / \mathrm{s} /\end{array}$ \\
\hline 3 & $\begin{array}{c}/ \mathrm{g} /, / \mathrm{s} /, / 3 /,\{s\} \\
/ \mathrm{t} / \mathrm{d}, / \mathrm{d} z /, \text { enc. } \\
\text { cons. }\end{array}$ & $\begin{array}{c}/ S /, / 3 /, / t 5 / \\
/ d \mathrm{~d} /\end{array}$ & Hipernasalidade leve & Hipernasalidade leve & $\begin{array}{c}\mathrm{p} /, / \mathrm{t} /, / \mathrm{k} /, / \mathrm{f} / \\
/ \mathrm{s} /, / \mathrm{s} /\end{array}$ & $\begin{array}{l}\mathrm{p} /, / \mathrm{t} /, / \mathrm{k} /, \\
/ \mathrm{f} /, / \mathrm{s} /, / \mathrm{s} /\end{array}$ \\
\hline 4 & $\begin{array}{c}/ \mathrm{t} /, / \mathrm{d} /, / \mathrm{g} /, / \mathrm{l} / \\
/ \mathrm{k} /, / \mathrm{g} /, / \mathrm{s} /, / \mathrm{z} / \\
/ \mathrm{J} /, / 3 /, / \mathrm{t} /\end{array}$ & $\begin{array}{l}/ \mathrm{s} /{ }^{*}, / \mathrm{z} /{ }^{*}, / \mathrm{S} /{ }^{*}, \\
/ \mathrm{z} /{ }^{*}, / \mathrm{t} / /^{*}, / \mathrm{d} /^{*}\end{array}$ & $\begin{array}{l}\text { Hipernasalidade } \\
\text { moderada }\end{array}$ & $\begin{array}{l}\text { Hipernasalidade } \\
\text { moderada }\end{array}$ & $\begin{array}{l}/ \mathrm{p} /, / \mathrm{t} /, / \mathrm{k} / \\
/ \mathrm{f} /, / \mathrm{s} /, / \mathrm{s} /\end{array}$ & $\begin{array}{l}/ \mathrm{p} /, / \mathrm{t} /, / \mathrm{k} /, \\
/ \mathrm{f} /, / \mathrm{s} /, / \mathrm{s} /\end{array}$ \\
\hline
\end{tabular}

* somente na fala espontânea 


\section{Caso 1}

$\mathrm{Na}$ avaliação final, observou-se que a fala do paciente continuou com hipernasalidade leve, mas passou a apresentar produção correta dos fonemas /t/, /d/, /g/, /f/, /v/, / $/$ e /3/; substituição assistemática de /s/ por $/ \mathrm{S} / \mathrm{,} / \mathrm{z} /$ por $/ 3 /, \mathrm{t} \int /$ por $/ \mathrm{S} /$ e /dz/ por /3/ e escape de ar nasal em sílabas com /s/ e /S/, palavras com /f/ e /s/ e frases com / /. Portanto, ao final das sessões houve a adequação do ponto articulatório das oclusivas /t/ e /d/ que eram produzidas como PDMP, das fricativas /f/ e /s/ produzidas anteriormente como fricativa faríngea, de /v/ e /z/ que eram substituídas por /g/, e /S/ e /3/ produzidas como fricativa nasal posterior. Houve também adequação da oclusiva /g/ que era dessonorizada assistematicamente. Apesar da paciente já apresentar o ponto articulatório correto das fricativas /s/ e /z/, ainda fazia substituições assistemáticas por / $/$ e /3/, respectivamente, na fala espontânea. Permaneceu a dificuldade na produção dos africados, continuando o /t $\int /$ sendo substituído pelo $/ \int /$ e o $/ \mathrm{d} z /$ que passou a ser substituído por /3/ no lugar do /g/, mostrando um controle maior no direcionamento do fluxo aéreo para a cavidade oral. Não ocorria mais o ronco nasal durante a produção das fricativas /z/, / / e do africado /dz/, nem escape de ar nasal em frases com /p/, /t/, /f/ e /s/. Continuavam o escape de ar nasal em palavras com /f/ e /s/ e hipernasalidade leve.

\section{Caso 2}

$\mathrm{Na}$ avaliação final, foi observado que o paciente continuava a apresentar hiponasalidade moderada, passou a apresentar produção correta dos fonemas /b/, /t/, /d/, /f/, /v/, /z/, $/ \mathrm{S} /, \mathrm{z} / \mathrm{e} / \mathrm{d} 3 /$; fricativa faríngea no $/ \mathrm{s} /$ apenas durante a fala espontânea e escape de ar nasal em sílabas com /k/, /f/, /s/, /S/, palavras com /f/, /s/, / / e frases com /t/, /f/, /s/ e /S/. Observou-se, desta forma, a adequação do ponto articulatório dos fonemas /t/ e /d/ que eram produzidos como PDMP e dos fonemas $/ \mathrm{s} / \mathrm{e} / \mathrm{S} /$, anteriormente produzidos como fricativa faríngea. Houve adequação na pressão intra-oral na produção dos fonemas /b/, /f/, /v/, /z/, /3/ e /dz/. Na fala espontânea permaneceu a fricativa faríngea na produção do /s/. Observou-se também a permanência do escape de ar nasal em palavras e frases com /f/, /s/, / / e a presença deste em sílabas com $/ \mathrm{k} /, / \mathrm{f} /, \mathrm{s} /, / \mathrm{J} /$ e frases com /t/, que não ocorriam na avaliação inicial.

\section{Caso 3}

$\mathrm{Na}$ avaliação final, foi observado que o paciente continuava a apresentar hipernasalidade leve, porém com produção correta dos fonemas /p/,/ t/, /g/, /z/, \{s \}. Houve ainda a adequação da pressão intra-oral nos fonema /p/, /t/ e /z/, com permanência de fraca pressão no /v/. Assim sendo, houve adequação na produção do fonema /g/ que era substituído por $/ \mathrm{d} /$, e do arquifonema $\{\mathrm{s}\}$ anteriormente produzido como fricativa faríngea. As fricativas $/ S /$ e $/ 3 /$ continuavam sendo substituídas por /s/ e /z/ respectivamente, porém de modo assistemático. Permaneciam as omissões dos africados $/ \mathrm{t} \int / \mathrm{e}$ /dz/ e dos grupos consonantais com /1/ e o escape de ar nasal em sílabas, palavras e frases com /p/, /t/, /k/, /f/, /s/ e /S/. Apresentava produção do grupo consonantal com /r/, porém com epêntese, e emissão de ar nasal no /s/, que não ocorria anteriormente.

\section{Caso 4}

$\mathrm{Na}$ avaliação final a paciente continuava a apresentar hipernasalidade moderada; produção correta dos fonemas estimulados em fala dirigida, continuando com fraca pressão intra-oral nos fonemas /b/, /d/ e /g/; coarticulação com golpe de glote no $/ \mathrm{k} /$ somente quando associado à vogal $/ \mathrm{i} /$; fricativa faríngea nos fonemas /s/, /z/, / $/, / 3 /, / \mathrm{t} \int /, / \mathrm{d} 3 /$, assistematicamente na fala espontânea; escape de ar nasal em palavras com /t/, /k/, /S/ e frases com /p/, /t/, /k/, /f/, /s/ e / $/$. Neste caso, portanto, mostravam-se adequados ao final das sessões os pontos articulatórios dos fonemas /t/, /d/ que apresentavam PDMP e projeção de língua, e do fonema /s/ que apresentava PDMP, na avaliação inicial. O /g/ que apresentava PDMP e golpe de glote, encontrava-se após a terapia intensiva com ponto articulatório adequado, mas com fraca pressão intra-oral. A oclusiva $/ \mathrm{k} /$, anteriormente produzida com golpe de glote, encontrava-se corretamente articulada quando associada às vogais $/ \mathrm{a} /, / \mathrm{e} /, / \mathrm{o} /, / \mathrm{u} / \mathrm{e}$ coarticulada com golpe de glote quando associada à vogal /i/, ainda que assistematicamente. Estavam adequados também os pontos articulatórios das fricativas /s/, /z/, / /, /3/ e da africada /t $\int /$ na fala dirigida, porém apresentando fricativa faríngea de modo assistemático na fala espontânea. Continuavam com fraca pressão intra-oral os fonemas /b/, /d/, /g/ e o escape de ar nasal em palavras com /t/, /k/, / / e frases com /p/, /t/, /k/, /f/, /s/ e /S/.

\section{DISCUSSÃO}

As alterações comunicativas que resultam da fissura labiopalatina são muitas e dificultam a compreensão da fala pelo ouvinte. A fala nasalizada é, além disso, estigmatizada, sendo motivo de zombarias e piadas ${ }^{(4)}$. Percebeu-se que os portadores de fissura labiopalatina atendidos no programa de terapia intensiva eram bem compreendidos por seus familiares, porém, encontravam dificuldade de comunicação com pessoas que não eram de sua convivência diária. Estas alterações de fala podem resultar em prejuízos para a vida escolar, social e principalmente para o mercado de trabalho, onde esses pacientes encontram resistência das pessoas em contratá-los para determinados serviços. Como conseqüência, a qualidade de vida é afetada, o que pôde ser observado por uma queda na auto-estima dos pacientes atendidos.

Alguns autores relatam que a inteligibilidade de fala dos portadores de fissura palatina é influenciada por fatores como: articulação, ressonância, emissão de ar nasal, fonação, velocidade de fala, fluência e entonação, além das características do falante e de sua familiaridade com o ouvinte ${ }^{(10)}$. No presente trabalho, observou-se que outros fatores, além dos distúrbios articulatórios compensatórios e alterações de ressonância, também interferiam na inteligibilidade de fala dos pacientes. Encontrou-se nestes, substituições e omissões de fonemas, velocidade de fala aumentada, fala pouco articulada e pouco modulada. Além disso, características como timidez e baixa auto-estima foram fatores que influenciaram na 
comunicação. Isto fez com que os pesquisadores modificassem e adaptassem as estratégias terapêuticas, visando atender às necessidades que foram observadas nos pacientes durante os atendimentos. Em vista disto, procurou-se utilizar, não somente uma abordagem articulatória, mas também a associação com uma abordagem fonológica (pistas auditivas, melhora na auto-percepção e percepção da fala do outro), vocal (projeção e ressonância) e prosódica (velocidade de fala, modulação), tratando os distúrbios apresentados, visando à integração adequada dos mesmos ao ambiente familiar e social ${ }^{(10-11)}$. Acredita-se que esta associação de abordagens, bem como a inclusão de sessões em grupo, e não apenas a freqüência das sessões, tenha contribuído para a boa evolução dos casos atendidos.

Com relação à abordagem articulatória, buscou-se direcioná-la para a eliminação dos distúrbios articulatórios compensatórios, tendo como base o direcionamento oral do fluxo aéreo, de forma que o modo articulatório (oclusivo, fricativo) pudesse ser obtido por meio do uso de pontos articulatórios orais adequados ${ }^{(5,10)}$. Na colocação dos pontos articulatórios corretos dos fonemas, seguiram-se as etapas de produção do fonema isolado, em contexto silábico, vocábulos, frases, leituras, até a fala espontânea, com a utilização de pistas visuais, auditivas e tátil-cinestésicas, conforme sugerido na literatura ${ }^{(10,12)}$

A terapia diária, pela proximidade e freqüência dos encontros, possibilitou aos pesquisadores observar a gradativa modificação da fala dos pacientes, corrigindo-a sempre que preciso e auxiliando os pacientes na percepção de suas dificuldades e no modo correto de produção dos sons da língua. À medida que os pacientes foram percebendo melhoras em sua fala, passavam a ter maior envolvimento e comprometimento com a terapia.

Ao final do período de terapia intensiva, todos os pacientes apresentaram melhora significativa na fala com adequação dos pontos articulatórios dos fonemas estimulados, em especial dos DAC. Isto vem corroborar com relatos de outros autores sobre a melhor evolução terapêutica nos indivíduos portadores de DAC quando existe a prática diária e freqüente dos exercícios de forma correta ${ }^{(7,9)}$.

Encontrou-se na literatura controvérsias em relação ao tempo de fonoterapia. Há autores que preconizam atendimentos breves com atendimentos de 15 a 20 minutos, cinco dias por semana ou de 20 a 30 minutos, três dias por semana, considerando, ainda, terapias com uma hora de duração como muito longas ${ }^{(7)}$. Outros relatam resultados satisfatórios com terapias de quatro horas diárias, com atividades variadas ${ }^{(14)}$. Acredita-se que a abordagem utilizada neste trabalho, terapias de três horas diárias, não foi desgastante para os pacientes, devido ao fato de intercalar terapia individual com terapia em grupo, juntamente com a utilização de estratégias e atividades variadas, que estimulavam o envolvimento dos pacientes no processo terapêutico.

O grande envolvimento dos pacientes, com certeza, foi também fator importante para a melhora obtida. Tal envolvimento pode ser explicado, não apenas pelas estratégias utilizadas, mas também por serem todos adolescente/ adultos que, por sentirem os prejuízos de uma fala com inteligibilidade comprometida, estavam muito motivados em melhorar. Além disso, tiveram uma participação ativa durante todo o processo.

Apesar da boa evolução dos pacientes nesse período, a automatização dos novos padrões na fala espontânea ainda é um grande desafio. Percebeu-se que a presença de um familiar nas terapias teria sido de grande valor para o momento da automatização, pois, segundo os próprios pacientes, os familiares não os corrigem durante a fala porque conseguem compreendê-los. Se houvesse essa participação, esses saberiam como e quando corrigi-los. Isso está de acordo com o que já foi citado em literatura sobre a necessidade dos pacientes e os familiares serem bem orientados e treinados para a realização dos exercícios em casa, assim como a importância da participação da família na terapia ${ }^{(7)}$.

$\mathrm{O}$ fato de este estudo contar com uma amostra pequena foi decorrente da dificuldade, encontrada por muitos pacientes em se hospedar e se manter em Belo Horizonte durante 15 dias para o tratamento. Apesar de mostrarem interesse pela terapia, as condições sócio-econômicas foram um empecilho. Infelizmente, o CENTRARE ainda não dispõe de uma casa de apoio para acomodação desses pacientes.

Tendo em vista o resultado satisfatório da terapia em um período curto, sugere-se que novos trabalhos sejam realizados com um número maior de pacientes, com pacientes operados de fissura labiopalatina que apresentem somente hipernasalidade, com pacientes que apresentem outras alterações fonoaudiológicas e que a terapia intensiva faça parte da terapia convencional como um módulo inicial.

\section{COMENTÁRIOS FINAIS}

A terapia intensiva, da forma como foi realizada, mostrou ser uma alternativa eficaz e viável nos casos apresentados, podendo também ser uma estratégia a ser utilizada, na etapa inicial do tratamento fonoaudiológico convencional.

\section{AGRADECIMENTOS}

Agradecemos ao CENTRARE por nos possibilitar realizar este trabalho, disponibilizando suas instalações, funcionários e materiais no período de férias, assim como os pacientes e à fonoaudióloga Etienne Barbosa da Silva, pela realização das avaliações iniciais e finais dos pacientes. 


\begin{abstract}
Due to the lack of speech therapists at various regions of Brazil to assist patients with cleft lip and palate, new intervention programs must be developed for these individuals. Intensive speech therapy has been cited in literature as an alternative modality. This article relates the experience of four cleft lip patients, comparing their speech performances before and after the intensive intervention. The subjects, three adults and one adolescent with compensatory articulatory disorders, were engaged in an intensive summer training program. For each patient, intervention was carried out daily for three hours, during 10 days, divided into individual and group therapy. At the beginning and at the end of that period, patients were assessed by a speech therapist who did not participate in the sessions. A sample of spontaneous speech, counting from 1 to 20 and repetition of a list of words and sentences with oral occlusive and fricative phonemes were recorded on video tape. All patients showed satisfactory development with the intensive therapy program, adapting the worked phonemes in directed speech, but still requiring follow-up therapy to automatize their production. Intensive speech therapy was shown to be an efficient and possible alternative in these cases, and could also be a strategy at the beginning of conventional speech intervention.
\end{abstract}

Keywords: Speech therapy; Cleft palate; Speech/therapy; Velopharyngeal insufficiency; Adult; Adolescent

\title{
REFERÊNCIAS
}

1. Loffredo LCM, Freitas JAS. Prevalência de fissuras orais de 1975 a 1994. Rev Saúde Pública = J Public Health. 2001;35(6):571-5.

2. Nagem Filho H, Moraes N, Rocha RGF. Contribuição para o estudo da prevalência das más formações congênitas lábio-palatais na população escolar de Bauru. Rev Fac Odont São Paulo. 1968;6:111-28.

3. Amaral SA, Genaro KF. Análise da fala em indivíduos com fissura labiopalatina operada. Pró-Fono.1996;8(1):36-46.

4. Jesus MSV, Reis C. Estudo perceptivo das vogais orais e nasais de indivíduos com fissura palatal. J Bras Fonoaudiol. 2002;3(11):121-6.

5. Pegoraro-Krook MI, Souza JCRD, Teles-Magalhães LC, Feniman MR. Intervenção fonoaudiológica na fissura palatina. In: Ferreira LP, BefiLopes DM, Limongi SCO, organizadores. Tratado de fonoaudiologia. São Paulo: Roca; 2004. p. 339-455.

6. Pegoraro-Krook MI, Genaro KF. Comunicative disorders in craniofacial malformations. Braz J Dysmorphol Speech-Hear Dis. 1997;1(1):35-40.

7. Golding-Kushner KJ. Treatment of articulation and resonance disorders associated with cleft palate and VPI. In: Shprintzen RJ, Bardach J, editors. Cleft palate speech management: a multidisciplinary approach. St. Louis: Mosby; c1995. p. 327-51.

8. Vicente MCZ, Buchala RG. Atualização da terminologia de distúrbios articulatórios encontrados em falantes portadores de fissura de lábio e palato. Distúrb Comun. 1991;4:147-52.

9. Pamplona MC, Ysunza A, González M, Ramírez E, Patiño C. Linguistic development in cleft palate patients with and without compensatory articulation disorder. Int J Pediatr Otorhinolaryngol. 2000;54(2-3):81-91.

10. Genaro KF, Yamashita RP, Trindade IEK. Avaliação clínica e instrumental na fissura labiopalatina. In: Ferreira LP, Befi-Lopes DM, Limongi SCO, organizadores. Tratado de fonoaudiologia.São Paulo: Roca; 2004. p.45677.

11. Silva HS, Bordon AKCB, Duarte DA. Estudo da fissura labiopalatal. Aspectos clínicos desta malformação e suas repercussões. Considerações relativas à terapêutica. J Bras de Fonoaudiol. 2003;4(14):71-4.

12. Genaro KF. A terapia fonoaudiológica para correção da produção da fala nos casos com fissura labiopalatina já reparada. In: Comitê de Motricidade Orofacial da Sociedade Brasileira de Fonoaudiologia. Motricidade orofacial: como atuam os especialistas. São José dos Campos: Pulso Editorial; 2004. p. 211-9.

13. Ferreira AB. Saiba como está a distribuição de fonoaudiólogos na $6^{\text {a }}$ Região. Jornal CRFa 6r. 2002;15:6-7.

14. Pamplona C, Ysunza A, Patiño C, Ramírez E, Drucker M, Mazón JJ. Speech summer camp for treating articulation disorders in cleft palate patients. Int J Pediatr Otorhinolaryngol. 2005;69(3):351-9.

15. Di Ninno CQMS. Atendimento fonoaudiológico intensivo em módulos: relato de um caso operado de fissura labiopalatal [CD-ROM]. In: X Congresso Brasileiro de Fonoaudiologia; 2002. Belo Horizonte; 2002. 